\title{
ist \\ Estilo de raciocínio e capilaridade técnico-cultural na química no século xvIII
}

\author{
Ronei Clécio Mocellin
}

\begin{abstract}
茴
RESUMO

Neste artigo pretendo identificar um “estilo de raciocínio" próprio à química e apontar a disseminação de seus produtos e conceitos. O objetivo é o de explicitar alguns elementos que caracterizam o estilo de pensar e de fazer da química na segunda metade do século xvıı, sua capilarização técnico-cultural. O delineamento de um estilo químico de raciocinar origina-se da constância dos espaços técnico-epistêmicos em que o saber químico é construído. A química é uma ciência de laboratório, eminentemente técnica e operatória, quer dizer, trata-se de um conhecimento técnico-científico stricto sensu. Produtora de artefatos, a ciência química é inseparável da técnica, da tecnologia e da indústria, de maneira que sua identidade epistêmica é indissociável de sua história. Seu estilo caracteriza um valor profundo na cultura técnica do homo faber, do poder de agir sobre a natureza e de transformá-la através de manipulações e de rearranjos.
\end{abstract}

PALAVRAS-GhaVe • Estilo de raciocínio químico. Laboratório. Capilaridade técnico-cultural.

Século xvıı. Academia de Dijon. Tecnociência.

\section{INTRODUÇÃO}

A química é uma ciência histórica. Seus artefatos e suas teorias estão profundamente associados à historicidade das operações, das técnicas instrumentais, dos modos de produção e das instituições que a tornam possível em um determinado contexto. Isto sugere que o território de investigação dos químicos não pode ser delimitado atemporalmente, o que torna improvável qualquer definição a priori do que seja o conhecimento químico.

Admitindo essa contingência histórica, seria possível nos dotarmos de instrumentos conceituais capazes de oferecerem uma perspectiva mais global e uniforme da química e de seus artefatos sem nos comprometermos com fundamentos epistêmicos, ontológicos ou metodológicos estáticos para essa ciência em permanente transformação? Como conciliar o pluralismo derivado da história com uma uniformidade transhistórica demandada por uma narrativa filosófica? Sem a pretensão de responder a essas questões complexas, pretendo discutir aqui, através de uma contextualização 
histórica, dois conceitos gerais derivados de um diálogo estreito entre a história e a filosofia da química.

Os filósofos que nas últimas décadas têm tomado a química como território de investigação sustentam a identidade cognitiva dessa ciência. Embora divirjam em pontos importantes, esses filósofos têm chamado a atenção para a necessidade de analisar a química como uma ciência autônoma e não redutível, tanto ontológica (suas entidades) quanto epistemologicamente a uma ciência mais fundamental, como a física atômica. Para eles é de grande interesse filosófico estudar não apenas o nível de materialidade que compete à química, mas os modos de criação das teorias e das práticas empregadas pelos químicos, bem como os artefatos por eles produzidos (cf. Baird et al., 2006; Bensaude-Vincent, 2008a; 2008b).

$\mathrm{Na}$ esteira dessas investigações, este artigo tem por objetivo refletir sobre as questões acima a partir de dois conceitos filosóficos gerais e de uma descrição histórica contextualizada. O primeiro desses conceitos deriva da bem conhecida expressão "estilo de pensamento" ou "estilo de raciocínio" científico apresentada por diversos autores. A questão, a saber, é se existe um "estilo químico" de raciocinar e quais seriam suas características distintivas.

Apesar de seu caráter histórico não permitir fixar uma identidade cognitiva $a$ priori, a química guarda, contudo, a constância dos espaços técnico-epistêmicos em que é criada. Jamais houve química sem laboratórios, de maneira que poderíamos considerar como bastante plausível a ideia de que o laboratório dos químicos pode revelar alguns traços profundos que caracterizam o pensamento químico e sua forma de conceber e operar sobre os objetos materiais. O objetivo aqui é sustentar a ideia de que existe um "estilo químico" de raciocinar que tem sua origem exatamente na operacionalidade técnica e teórica criada por químicos e alquimistas em seus laboratórios.

Isso não significa que outras ciências não se tenham estabelecido a partir de investigações de laboratório, mas sugere que foi a química que originou essa maneira singular de produzir conhecimento científico. A partir desses espaços epistêmicos, a química se estabeleceu como parte da ciência em geral, aliando o trabalho de investigação empírica e produtiva com uma crescente institucionalização de seu ensino, da publicação de manuais e de periódicos, além da assimilação de seus conceitos como operadores em outros campos do conhecimento.

$\mathrm{O}$ segundo conceito, que não pretende ser mais que um esboço, deriva do ponto de vista que considera necessário compreender-se os modos de disseminação e de absorção dos produtos do conhecimento científico pelas sociedades e pelo ambiente natural. Um entendimento mais amplo e aprofundado desses processos deveria, sobretudo, contribuir nas tomadas de decisões (políticas, econômicas, industriais, éticas, axiológicas, pedagógicas) que dizem respeito à ciência e à tecnologia. Proponho o 
emprego do termo "capilaridade" para expressar esse movimento de difusão e de assimilação socioambiental do conhecimento científico e de seus produtos.

Certamente, com esse termo, não sugiro mais que uma imagem de semelhança com o conceito físico de capilaridade. Com essa analogia pretendo apenas indicar um movimento científico e social que se manifesta em condições precisas e que depende de um equilíbrio específico de forças e tensões. Para além dessa analogia, aqui a expressão "capilaridade técnico-cultural” servirá para denominarmos uma investigação acerca da "história das coisas" (materiais, teóricas e culturais) desde sua produção até seu "desaparecimento". Dado ser apenas um esboço para investigações posteriores, limitar-me-ei a uma descrição da capilarização da química extraída do contexto histórico do final do século xviıI.

Foi na química das luzes que se consolidou uma tradição filosófica segundo a qual o conhecimento da natureza não se dava diretamente, mas através de sua reconstrução em laboratório, um lugar destinado à experimentação e onde se fundiam os trabalhos manual e intelectual. Através de um conjunto de operações técnicas de base, como a maceração, o aquecimento, a dissolução e a cristalização, os químicos realizavam análises e sínteses que revelavam os procedimentos que lhes permitiam executar rearranjos materiais. Era em seus laboratórios que os químicos decompunham as substâncias em suas partes e as reconstituíam como prova do conhecimento de suas propriedades.

É justamente a racionalidade química emergente do laboratório do século das Luzes o tema principal deste artigo. Limitarei a investigação à França e, mais especificamente, à “cultura química” produzida em torno do laboratório de uma Academia de província. Essa contextualização histórico-geográfica visa analisar alguns casos precisos que nos ajudem a compreender desde as entidades teóricas imaginadas para explicar e criar fenômenos químicos até a produção efetiva de determinados materiais, além de possibilitar-nos lançar um olhar sobre a contribuição da ciência química na construção de um ideal de progresso.

\section{UM ESTILO QUímIGO DE RAGIOGINAR}

O conceito de estilo aparece mais frequentemente em discussões nos domínios da história e da crítica de arte. Para Nelson Goodman, por exemplo, nesses domínios, o conceito tinha a ver exclusivamente com o funcionamento simbólico de uma obra enquanto tal. Ele estava em várias espécies de propriedades simbólicas que permitiam atribuir a uma obra um autor, um período, um local ou uma escola (cf. Goodman, 1995). Chunglin Kwa demonstrou que foi no final do século xix que o historiador da arte Alois Riegl utilizou pela primeira vez a palavra para designar diferentes tradições artísticas, con- 
siderando-as como uma "questão de estilo" (cf. Kwa, 2012, p. 611). Porém, filósofos e historiadores da ciência também fizeram uso desse conceito na identificação de racionalidades próprias ao conhecimento científico.

O médico e filósofo da medicina Ludwik Fleck foi um dos primeiros a empregar a expressão "estilo de pensar" na descrição da construção histórica, epistemológica e experimental do conceito de sífilis. Para ele, não existia um descobridor da sífilis, pois tal conceito representava um fato científico que era o resultado de um estilo de pensamento praticado por um coletivo de pesquisadores (cf. Fleck, 2010, p. 49). De Fleck, gostaria de reter a ideia de que um estilo corresponde a uma forma de produzir fatos científicos, atestados pela coletividade de praticantes da área.

Enquanto Fleck identifica o conceito em um coletivo disciplinar, em um conjunto de práticas circunscritas a uma área específica de investigação, o historiador das ciências Alistair Crombie, em sua extensa narrativa acerca do desenvolvimento das ciências no Ocidente, apontou a generalidade e a longa duração de alguns "estilos de pensamento" científicos. Crombie identifica esses estilos e os associa a certos métodos e mentalidades condicionadas pela formulação de atividades-problema e na busca de suas soluções. Ao longo do desenvolvimento histórico das ciências no Ocidente, Crombie sugere seis estilos científicos de pensar: (1) postulações matemáticas; (2) exploração experimental e mensurações; (3) construção hipotética de modelos; (4) comparação e taxionomia; (5) análise estatística e cálculo das probabilidades e (6) derivação histórica do desenvolvimento genético (cf. Crombie, 1994). De Crombie, reterei a ideia de que certos estilos se desenvolvem em processos históricos de longa duração.

A descrição histórica desses diferentes estilos de fazer ciência teve influência sobre o filósofo Ian Hacking, que propôs uma análise filosófica do termo "estilo" (cf. Hacking, 2002b). Segundo Hacking, (1) existem diferentes estilos de raciocínio e cada um tem sua trajetória e maturação; (2) é a partir do estilo de raciocínio em que uma proposição é gerada que se pode decidir se ela é verdadeira ou falsa; (3) daí que muitas possibilidades do que pode ser verdadeiro ou falso dependem de eventos históricos, a saber, do desenvolvimento de certos estilos de raciocínio; (4) por isso, pode-se inferir que existem outras categorias de possibilidade para além das que existem em nossa tradição e (5) não podemos raciocinar para determinar se sistemas alternativos de raciocínio são melhores ou piores do que o nosso, porque as proposições sobre as quais raciocinamos obtêm seu sentido apenas no estilo de raciocínio empregado (cf. Hacking, 2002a, p. 196).

Apesar de subscrever as principais conclusões de Crombie, Hacking considera inadequado o uso da expressão "estilos de pensar", pois, segundo ele, ela indicava algo demasiadamente restrito à esfera intelectual. Hacking sugere, então, empregar a expressão "estilos de raciocínio" para identificar os diversos padrões de racionalidades 
científicas existentes. Segundo ele, a palavra "raciocínio" expressa melhor uma atividade intelectual realizada em público, enquanto o termo "pensamento" tinha elevada conotação subjetiva . Hacking considera que Crombie tinha dado demasiado privilégio a uma "história da argumentação", talvez por influência de Alexandre Koyré, seu antigo professor, e de sua "história do pensamento científico". Além desse caráter público, Hacking considera que o uso do termo "raciocínio" seria mais adequado para expressar que a "objetividade" da ciência derivava não apenas de argumentações e de demonstrações, mas também de manipulações e de intervenções (cf. Hacking, 2002a, p. 200).

Meus estilos de raciocínio, eminentemente públicos, fazem parte do que precisamos para entender o que queremos dizer com objetividade. Isso não é assim porque os estilos são objetivos (ou seja, que encontramos as melhores maneiras imparciais de chegar à verdade), mas porque eles estabeleceram o que quer dizer ser objetivo (verdades de certos tipos que são o que obtemos quando fazemos certos tipos de investigação, ao satisfazermos a certos padrões) (Hacking, 2002b, p. 202).

Essa mudança de nomenclatura também serviu a Hacking para acentuar sua abordagem filosófica das diferentes tradições de produção de conhecimento científico, na qual cada estilo torna-se "independente de sua própria história" (p. 209). O surgimento e a autonomização de um estilo são contingentes, e devem ser descrito pelos historiadores, mas, uma vez estabilizados, "cada estilo passava a ser o que vemos como um cânone um tanto atemporal de objetividade, um padrão ou modelo do que era ser razoável sobre esse ou aquele tipo de assunto" (p. 209). Cada estilo de raciocínio científico introduz, assim, novos tipos de objetos, de evidências, de leis e de proposições candidatas a serem verdadeiras ou falsas:

Cada estilo introduz vários tipos de novas entidades. Vejamos os objetos. Cada estilo de raciocínio está associado a um debate ontológico sobre o novo tipo de objeto. (...) Cada estilo de raciocínio tem seu próprio debate sobre a existência, porque o estilo introduz um novo tipo de objeto, individuado por meio do estilo, e não perceptível anteriormente entre as coisas que existem (Hacking, 2002b, p. 211).

Outra particularidade de Hacking é a de identificar a existência de um "estilo de laboratório", que tinha ficado difuso entre os estilos (2) e (3) de Crombie. Segundo ele, esse estilo caracteriza-se 
pela construção de aparelhos para produzir fenômenos para os quais a modelagem hipotética podia ser verdadeira ou falsa, mas usando outra camada de modelagem, a saber, modelos de como os próprios aparelhos e instrumentos funcionam e começou por volta da época em que Robert Boyle fez seu compressor de ar (Hacking, 2002b, p. 205).

Trinta anos depois, Hacking (2012) reafirma suas ideias principais e aponta que o livro de Steven Shapin e Simon Schaffer (1985) demonstra exatamente o que ele tinha em mente ao falar em "estilo de laboratório" (Hacking, 2012, p. 6o3).

É curioso que nem Crombie nem Hacking, ao descreverem o que entendiam por "estilo experimental" ou "estilo de laboratório", deram atenção à produção do conhecimento químico. Aliás, nenhum dos dois situou com precisão em qual de suas listas de estilos enquadrariam a química. No caso de Hacking, isso é ainda mais intrigante, pois ele postula a existência de um estilo sem interrogar a disciplina científica na qual esses "espaços técnico-epistêmicos" foram efetivamente criados (cf. Smith, 2000).

Apesar desse esquecimento, Bernadette Bensaude-Vincent considera que o conceito de estilo desenvolvido por esses autores é uma ferramenta analítica que também poderia ser empregada na análise histórica e filosófica da química (cf. BensaudeVincent, 2009). Porém, segundo ela, embora Hacking tenha dado mais atenção ao papel da "manipulação" e da "intervenção" experimental operada em laboratório, ele não difere de Crombie quanto à ideia de "experimentação" como realização de um modelo mental, de um pensamento que antecipa a experiência (p. 369). Ambos negligenciaram a emergência de uma prática alternativa de experimentação significando a criação de fenômenos e a produção de artefatos. (p. 37o). A essa forma alternativa de experimentação Bensaude-Vincent chama de "estilo químico" de raciocinar, que seria um conceito capaz de reunir diferentes identidades cognitivas construídas pela química ao longo de sua história. Na verdade, o "estilo de laboratório" de Hacking não seria mais do que a extensão de um estilo forjado no laboratório de alquimistas e químicos.

Bensaude-Vincent aponta três razões para adotar a ferramenta analítica desenvolvida por Hacking nos domínios da química. A primeira consiste no fato de que Hacking considera que cada estilo cria seus próprios objetos, de modo que distintos estilos de raciocínio científico geram suas próprias ontologias, ou seja, postulam a existência de entidades que somente fazem sentido teórico ou experimental no domínio do próprio estilo. A segunda razão é a ênfase dada por Hacking de que, embora os estilos de raciocínio sejam produtos de uma história contingente, eles transcendem sua origem histórica e tornam-se padrões ou cânones de verdade. Assim, os estilos são prescritivos, eles prescrevem não somente o que é verdadeiro ou falso, mas também o 
que é ou não pensável. Em termos epistemológicos, eles originam uma nova racionalidade científica. Enfim, a terceira razão é o fato de que Hacking, assim como Crombie, consideram que estilos de raciocínio científico têm uma história de "longa duração", o que é essencial no caso de uma ciência como a química (cf. BensaudeVincent, 2009, p. 368-9).

Segundo Bensaude-Vincent, o "estilo químico" apresenta três características marcantes: (1) trata-se de um modo de conhecer através do fazer; (2) seu interesse principal está na individualidade material e não no estudo da matéria em geral e (3) representa um compromisso específico com a natureza. A partir de seus laboratórios, os químicos consolidaram uma tradição segundo a qual conhecer é sinônimo de saber-fazer, de modo que o conhecimento da natureza se dá a partir de sua reconstrução técnica (p. 37o). O objetivo principal é produzir artefatos. Portanto, um dos elementos centrais de um "estilo químico" de raciocinar consiste na tecnicidade operatória que leva à produção de um artefato, de um objeto artificial que pode, ou não, ter um exemplar na natureza (cf. Bensaude-Vincent, 2009, p. 375).

Mas, quais entidades povoam o laboratório dos químicos? Quais técnicas instrumentais estabelecem a existência de tais entidades? Como essas entidades são classificadas? Como nomeá-las? Mais do que oferecer uma explicação do mundo natural, de sua estrutura material, as entidades postuladas pelos químicos constituem instrumentos de ação sobre ele. Embora o objetivo fosse conhecer as propriedades das substâncias individuais, o "estilo químico" não implica um "substancialismo". Pois, indo além das substâncias concretas macroscópicas que constituem os corpos simples ou compostos, o químico postula a existência de seres individuais definidos pela sua capacidade de entrar em relação como outras entidades individuais. Assim, outra originalidade de um "estilo químico" provém do fato de que as entidades inobserváveis não são consideradas como chaves de explicação do mundo, que oferecem a razão das aparências, mas como instrumentos para agir.

Em relação à natureza, o filósofo Joachim Schummer identifica três noções que acompanharam a história da química: uma estática, uma teleológica e outra dinâmica. Por exemplo, a interpretação de que a arte alquímica alterava a criação divina foi própria de filósofos cristãos próximos ao neoplatonismo e corresponde a uma noção estática de natureza, ou seja, de que tudo o que é natural originou-se no ato da criação. Outros filósofos cristãos, como Tomás de Aquino e Alberto o Grande, adotaram o conceito teleológico aristotélico de natureza, que considerava existir um movimento natural em direção a um estado de perfeição, próprio de cada ser. De um ponto de vista teleológico, a alquimia imitava, ajudava e podia mesmo ultrapassar a natureza. Tanto na noção estática quanto na noção teleológica admite-se uma oposição por princípio entre os produtos da arte e produtos naturais. Na primeira, o natural seria caracteriza- 
do por alguma essência original, na segunda por um princípio motor (que a partir do século xviII será identificado a uma força vital). Enfim, a partir do século xvıI e inspirada nos trabalhos de Paracelso e de Pico della Mirandola, emergiu uma noção dinâmica de natureza, que não mais pré-supunha uma dicotomia fundamental entre o natural e o artificial (cf. Schummer, 2003, p. 713).

Essa imagem dinâmica de natureza consolida-se na química do século xvııI. Por exemplo, um dos principais programas de investigação estabelecido pela Academia de Ciências de Paris no início desse século, e que se perpetuou ao longo dele, foi o estudo da dinâmica química dos "sais" (na época o termo englobava não apenas o que hoje chamamos de sais, mas também o que identificamos como ácidos e bases), que teve na sistematização oferecida pela Tabela de relações de Etienne-François Geoffroy (1718) um poderoso instrumento pedagógico e de orientação experimental. Nesse programa, os sais não eram mais considerados como princípios, mas como produtos de certas combinações. Foi em decorrência dessa imagem dinâmica de natureza que Henri Louis Duhamel du Monceau conseguiu isolar um álcali fixo que entrava na composição do sal marinho, demonstrando que o sal marinho obtido na combinação desse álcali com ácido marinho era idêntico ao colhido nas salinas. Ou seja, não havia nenhuma diferença entre o sal artificial e o sal natural (cf. Duhamel du Monceau, ${ }_{17} 37$ ).

Enfim, como produtora de artefatos, a ciência química era inseparável da técnica, da tecnologia e da indústria. A partir de seus laboratórios os químicos consolidaram uma tradição que consiste em ocupar-se com investigações sobre os diferentes materiais, naturais ou artificiais. Além disso, a química tem a particularidade de não só produzir os objetos de seu estudo, mas também de controlá-los e reproduzi-los em escalas variáveis, de modo que seu estilo de manipular e agir sobre o mundo material e social apresenta um caráter essencialmente tecnocientífico (cf. Lefèvre, 2005, p. 194).

Assumindo a existência de um estilo de raciocínio próprio à química, estruturado em torno do laboratório químico, o meu interesse volta-se agora às especificidades desse estilo nos contextos históricos e sociais que tornaram possível sua exististência. Passo assim a fazer alguns comentários gerais acerca do lugar em que a química do século xviıI era produzida.

\section{O LABORATÓRIO QUímiGo DAS LUZES}

A estrutura física dos lugares em que o conhecimento químico é praticado ao longo do século Xviı variava de acordo com os objetivos e os meios econômicos, institucionais e humanos disponíveis. As investigações históricas desses lugares oferecem uma riqueza de detalhes acerca da química neles praticada e da disseminação de seus produtos. 
Essas investigações revelam a importância das atividades práticas, das redes de comunicação, da circulação de pessoas, de livros, de objetos materiais, da organização física desses espaços, na caracterização de uma identidade química daquele período (cf. Perkins, 2013).

Jon Eklund foi um dos primeiros a tentar compreender o químico das Luzes em seu trabalho de laboratório, descrevendo seus equipamentos, seus procedimentos habituais e as substâncias químicas utilizadas (cf. Eklund, 1975). Frederic Holmes demonstrou que, no espaço dos laboratórios, articulava-se um éthos institucional que fazia da química não apenas uma ciência experimental, mas um domínio de investigação cada vez mais dinâmico e produtivo. Holmes também aponta que a estabilidade instrumental desses espaços epistêmicos - pois o repertório de aparelhos e as operações efetuadas nos laboratórios em 1750 não eram muito diferentes daqueles descritos por Andreas Libavius (1555-1616) em seu Alchemia (1597) " não significa um imobilismo. Na verdade, as melhorias técnicas e a invenção de instrumentos para medir novas informações acerca dos materiais analisados são permanentemente incorporadas ao acervo tradicional (cf. Holmes,1989).

Consolidou-se, assim, a imagem do laboratório como um teatro de operações químicas e instrumentais, de transformações qualitativas e quantitativas que proporcionam novos conhecimentos acerca dos materiais e dos corpos químicos que os constituem. Ursula Klein e Wolfgang Lefèvre demonstram de forma convincente que a química daquele período é efetivamente uma ciência dos materiais, a única que se ocupava da investigação e da manipulação das diferentes espécies de substâncias. As operações químicas também são vistas como um estágio avançado do empirismo, pois transcendiam à simples organização de fatos e estavam sujeitas a um controle instrumental preciso (cf. Klein \& Lefèvre, 2007, p. 1-3).

Desses espaços nasceu uma cultura química que identificava uma coletividade de praticantes. Essa cultura era constituída de atitudes práticas, gestos, teorias, instrumentos, produtos, manuais e métodos de ensino, traduções, correspondências, formas simbólicas, e interessava a um público bastante amplo. Além de um estilo de raciocínio próprio, os valores da química se disseminavam pela sociedade gerando desde resultados práticos até intrincados debates filosóficos. Porém, aqui, explicitaremos apenas alguns elementos dessa cultura específica e sua capilarização em outros níveis de organização social.

Como estudo de caso, proponho uma investigação da cultura química produzida em torno do laboratório da Academia de Ciências de Dijon a partir de 1776, cujo principal promotor e organizador foi Louis-Bernard Guyton de Morveau (cf. Lamarre, 1999; 2000). Ensino, pesquisa, expertise, traduções, inovação técnica e industrial eram os eixos diretores do programa de investigação levado a termo por Guyton de Morveau e 
seus colaboradores nesse laboratório, quase todo financiado pelo poder público, o estado da Borgonha.

Antes de entrarmos no laboratório da Academia de Dijon, convém observar que os traços do estilo químico que daí emerge não esgotam nem as possibilidades técnicas das operações químicas e instrumentais, nem a escolha dos conceitos usados nas explicações teóricas. Na verdade, a imagem da química que esse laboratório projeta representa particularmente as investigações sobre as combinações químicas possibilitadas pelas "dissoluções", obtidas pelo fogo ou por dissolventes. A química praticada por Guyton de Morveau e seus colaboradores está totalmente organizada em torno do conceito técnico-operatório das afinidades químicas (cf. Kim, 2003, p. 222-33).

A centralidade desse conceito na química desenvolvida por Guyton de Morveau constituía, com efeito, uma mudança importante na argumentação teórica utilizada pelos químicos da segunda metade do século xviı na justificação operatória das transformações químicas. Na Enciclopédia de Diderot e d'Alembert, bem como nos livros de Pierre-Joseph Macquer, um dos principais químicos da época, era o conceito de mixto, introduzido por Georg-Ernst Stahl para diferenciar a "união agregativa" (mecânica) da "união mixtiva" (química), que ocupava uma posição central (cf. Lehman, 2009, p. 102-3). Isso não significa, certamente, que os "mixtos químicos" (que representavam diferentes níveis de composição material) também não estivessem submetidos às mesmas forças da mecânica (gravitação newtoniana), mas o conceito de "afinidades químicas" como um caso particular das "atrações universais" tornava obsoleto o termo "mixto", que começou a desaparecer do vocabulário dos químicos.

Embora esse território de investigações fosse o mais vasto e desenvolvido, o que fez Antoine de Lavoisier considerá-lo como "a parte da química mais suscetível de tornar-se um dia uma ciência exata" (Lavoisier, 1789, p. xiii), os interesses da química não se reduziam a esse domínio. Se visitássemos o laboratório de Lavoisier, por exemplo, perceberíamos que o foco principal de investigação não era o mesmo que o de Dijon. A fortuna de Lavoisier permitiu levar adiante investigações que em nenhum outro laboratório eram possíveis. Em todos os laboratórios bem equipados como aquele da Academia de Dijon realizavam-se experimentos com os novos ares (gases) que começavam a ser isolados. Todavia, em nenhum deles com o grau de precisão alcançado pelos novos instrumentos utilizados por Lavoisier. Foi no território da química pneumática que Lavoisier concentrou suas investigações e cujos resultados sustentavam uma nova teoria química que foi reconhecida como uma revolução química (cf. Beretta, 2009).

Ademais, a nova constelação de materiais criados nos laboratórios suscitava um problema permanente para os químicos, o de nomeá-los e de classificá-los. O universo experimental criado no laboratório e a necessidade de comunicação fomentaram o 
desenvolvimento de um novo instrumento linguístico capaz de "dizer" sobre as coisas do "mundo químico" e, ao mesmo tempo, de ser de domínio público e não uma linguagem de iniciados (cf. Dagognet, 2002). Embora não seja objeto aqui, cabe apenas lembrar que para ficarmos atualizados sobre o assunto não precisaríamos sair do laboratório da Academia de Dijon, pois foi justamente seu professor quem primeiro desenvolveu um sistema completo de nomenclatura química (cf. Guyton de Morveau, $\left.17^{82}\right)$.

Na sequência, descreverei quatro exemplos da química praticada no laboratório da Academia de Dijon e do uso social de seus produtos. O primeiro trata da tentativa de medir quantitativamente as afinidades químicas, as forças responsáveis por todas as operações químicas. O segundo aponta o desenvolvimento de uma nova técnica que permitia uma manipulação operacional controlada das "relações" indicadas nas Tabelas de afinidades. Trata-se da titulação com uso de um novo instrumento inventado por Guyton de Morveau, a bureta. O terceiro exemplo serve para indicarmos a conexão da química praticada em laboratório com a produção industrial. Enfim, o quarto exemplo narra a epopeia técnica e midiática que foi a construção em 1784, e 1784 pela Academia de Dijon de um balão tripulado e cheio com "ar inflamável”.

\section{CapilarizaçÃo tÉGnico-GUltural}

Em novembro de 1774, em uma seção pública da Academia de Dijon, Guyton de Morveau leu uma dissertação na qual demandava às autoridades da Província a criação de um curso de química, que deveria ser público e gratuito. Várias eram as razões apontadas por ele para esse investimento da parte do estado da Borgonha, mas as duas principais consistiam, primeiro, na inserção da academia na pesquisa de um ramo da física geral que estava em pleno desenvolvimento teórico e experimental e, segundo, nas possibilidades de uso do conhecimento químico em um grande número de atividades de interesse coletivo. Seria uma grande oportunidade para a Academia investigar essa ciência, pois

de toda a física geral, a química era a que estava mais ao seu alcance e aquela cuja aplicação era a mais familiar. Seus elementos são os mais necessários para aproveitar das riquezas da natureza, para apreciar as obras-primas das artes e dar-se conta de todas as invenções da indústria e de todos os detalhes da economia (cf. Guyton de Morveau, 1774, p. 2). 
O público esperado seria formado não apenas por apoticários e médicos, cujo emprego da química era constitutivo da própria profissão, mas por todos aqueles que desejassem esclarecer-se sobre uma ciência emergente e ficar a par do progresso científico em curso. $\mathrm{O}$ mais importante era o emprego adequado dos conhecimentos químicos em todas as atividades em que se fizesse necessário, da agricultura à metalurgia, passando pelo setor tintureiro e de manufaturas de diversos produtos.

O curso foi proferido nas dependências de um imóvel comprado pela Academia em 1773 , no qual estava instalado o laboratório. A ampliação desse laboratório permitia a "analise de remédios, de minérios, das águas minerais e da teoria dos processos", passando a assumir uma tripla função: lugar de ensino; lugar de produção de medicamentos e tinturas e lugar de expertise. O curso foi estabelecido em 1776 , oferecendo três lições semanais de abril a junho (cf. Annonces, Affiches de Bourgogne, 2 avril, p. 1).

Por não contar com um anfiteatro, essas lições eram dadas no próprio laboratório, de modo que os alunos deviam acompanhá-las em pé. Dada esta dificuldade, com a ajuda do médico Huges Maret e do botânico Jean-François Durande, Guyton de Morveau elaborou um manual de ensino que continha toda a teoria e a descrição das principais operações. Os alunos encontravam nos três volumes do Elementos de química teórica e prática uma disposição pedagógica inovadora, tanto na distribuição das matérias quanto na fundamentação teórica (cf. Guyton de Morveau, 1777-1778).

Seguindo os conselhos dados por Macquer no verbete "Laboratório" de seu Dicionário de química (1766), assim como através de uma troca epistolar, Guyton de Morveau construiu um "espaço epistêmico" adequado à prática da química. De acordo com a planta do edifício da Academia de Dijon, o laboratório ficava localizado no primeiro andar e possuía dois recintos ligados por um pequeno corredor (ver na fig. 1, as letras $n, m, s)$.

O recinto maior $\left( \pm 55^{\mathrm{m}^{2}}\right)$ servia para dispor os instrumentos e acolher os alunos. Certamente possuía uma Tabela de relações de Geoffroy em uma das paredes, pois a tabela tinha presença garantida em todos os laboratórios depois de sua publicação, em 1718. O recinto menor servia para guardar as substâncias químicas. Apesar de não se dispor de um inventário do laboratório, é possível ter uma ideia de sua organização e instrumentação a partir das cartas trocadas com Macquer e dos instrumentos e produtos indispensáveis à realização de todas as operações químicas. O laboratório era bem equipado, dispondo de vários tipos de fornos, vidrarias, balanças, termômetros, aerômetros, microscópio, bomba a vácuo, cuba pneumática, máquina elétrica e de todas as substâncias químicas necessárias (cf. Macquer, 1766; Lettres).

Além dos instrumentos materiais, quais as entidades abstratas utilizadas pelos professores de Dijon em suas explicações teóricas? Embora outros químicos também 


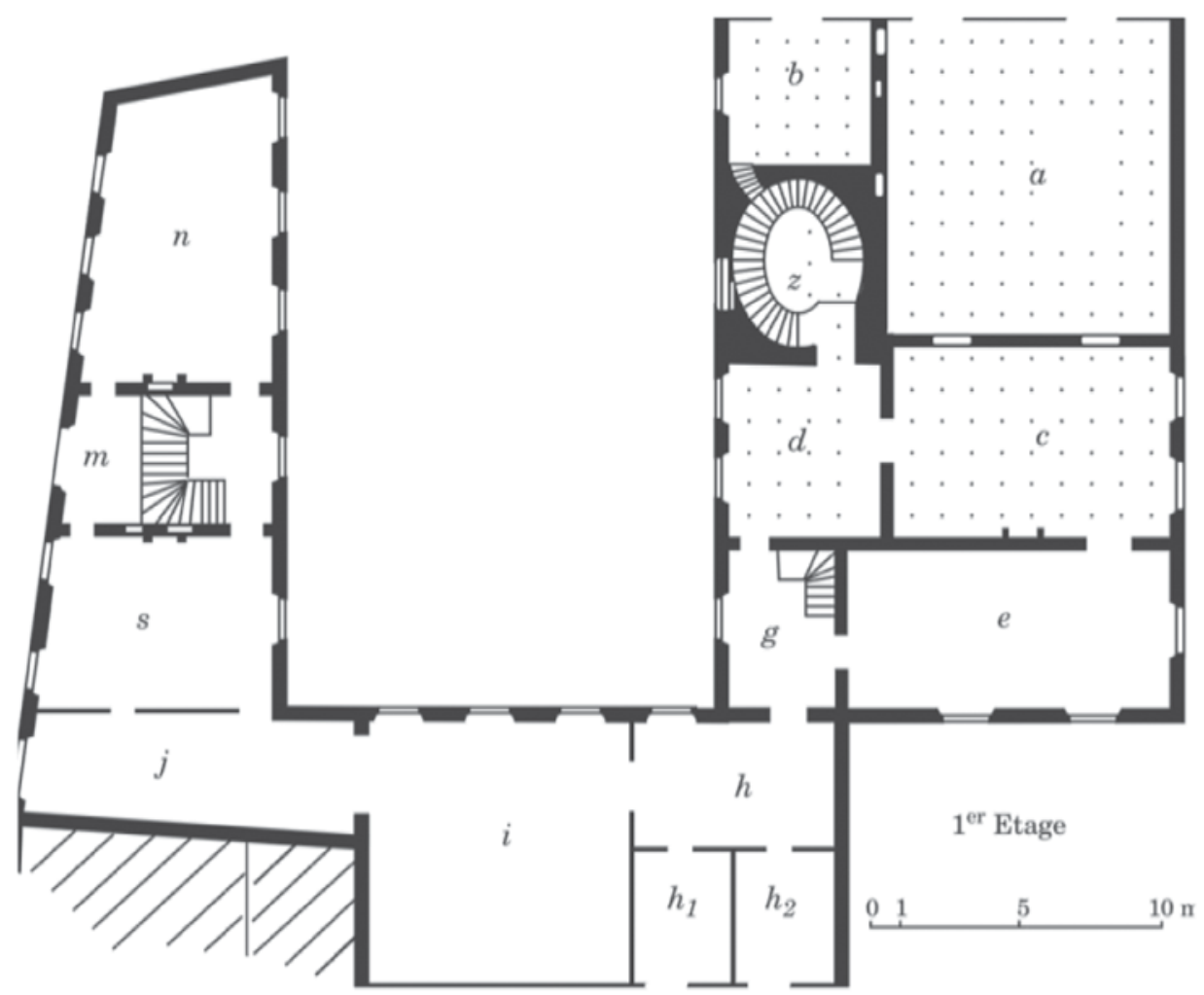

Figura 1. Planta do laboratório da Academia de Dijon - Mémoires de l'Académie des Sciences, Arts et BellesLettres de Dijon, t. 123, 1979 • p. 395 .

utilizassem o conceito de "afinidades químicas" em sentido newtoniano, os professores de Dijon optaram por estruturar toda sua argumentação teórica em torno dele. Todas as transformações químicas eram o efeito próximo da ação das afinidades entre as substâncias químicas. Conhecer como essas substâncias agiam umas sobre as outras permitia ao químico emitir um parecer sobre, por exemplo, a composição de um material analisado.

Os alunos que frequentavam os cursos de química oferecidos pela Academia eram introduzidos, assim, a um domínio teórico de vanguarda, cujo conceito central era o de que os corpos químicos estavam submetidos ao jogo das afinidades químicas. Um domínio cujo grande mestre era o químico sueco Torbern Bergman, com quem Guyton de Morveau mantinha intensa troca epistolar, além de ter traduzido vários textos seus para o francês. Na apresentação da tradução do primeiro volume dos Opuscules chymiques et physiques, Guyton de Morveau aponta um elemento comum entre ele e seu amigo Bergman na organização da prática e do ensino de química, pois, 
sobretudo, é a doutrina das afinidades explicada pela lei física universal da atração que, como já disse na Advertência do segundo volume do Eléments de Chymie da Academia de Dijon, tornou-se ao mesmo tempo, nos laboratórios de Uppsala e de Dijon, a chave de todas as operações que a arte demanda à natureza (Bergman, 1780, p. vi).

Porém, não se tratava de postular entidades inobserváveis para explicar um fenômeno, mas de somente admiti-las, se elas estivessem situadas em um quadro geral de relações e se agissem sobre outras entidades, sendo ainda indiferente que estivessem em composições minerais, vegetais ou animais.

O ideal era que os químicos dispusessem de meios instrumentais capazes de aferir valores às forças de afinidade entre essas entidades, podendo assim organizar de forma numérica suas relações, abrindo caminho para a aplicação, como dizia Lavoisier, de um "método geométrico" nas investigações químicas. Os meios técnicos disponíveis estavam longe desse ideal, de modo que na impossibilidade de medir diretamente as afinidades, a solução proposta por Guyton de Morveau foi a de estabelecer uma analogia entre a força de adesão e a força de atração (afinidade). Utilizando o método desenvolvido pelo físico inglês Brook Taylor, ele obteve valores que, no caso do mercúrio, correspondiam à ordem observada na Tabela de Geoffroy (cf. Guyton de Morveau, 1777, tomo 1, p. 65). Assim, mesmo que de forma precária, tornava-se possível especular sobre a possibilidade de uma operação química ocorrer, o que não deixa de ser de grande utilidade em um laboratório químico (cf. Mocellin, 2010, p. 204).

A medição das afinidades recebeu grande atenção da parte dos químicos nos anos 1780, e o desenvolvimento de uma nova técnica experimental por Guyton de Morveau foi de extrema importância. Essa nova técnica foi proposta a fim de resolver um problema que mobilizou o poder público e os químicos franceses: como aumentar a produção e a qualidade da pólvora para canhão fabricada no Reino? Para isso, um novo tipo de relação entre o estado e a política científica começou a surgir.

Em 1775, o ministro Anne Robert Jacques Turgot organizou, com a ajuda de Lavoisier, a criação de uma Administração da Pólvora e do Salitre. Segundo Patrice Bret, a organização da pesquisa científica e a divisão de trabalho imposta por esse órgão serviam de modelo à administração pública francesa. Na verdade, elas constituíam a origem de uma nova forma de intervenção do estado tanto na pesquisa científica quanto no seu uso social e sua aplicação generalizou-se durante e após a Revolução (cf. Bret, 1994).

Seguindo o programa de trabalho solicitado pela Administração, Guyton de Morveau e alguns associados criaram, em 1779, uma nitreria artificial em Dijon. Embora não tenham obtido grande sucesso econômico, essa empreitada industrial serviu ao desenvolvimento e à aplicação de uma nova técnica titrimétrica (gravimetria, volu- 
metria), que foi apresentada à Academia de Dijon em duas dissertações (cf. Guyton de Morveau, 1782, 1784a).

$\mathrm{O}$ salitre $\left(\mathrm{KNO}_{3}\right)$ era reconhecido como composto de ácido nitroso (nítrico, $\mathrm{HNO}_{3}$ ) e álcali vegetal (potassa, $\mathrm{K}_{2} \mathrm{CO}_{3}$ ). Nas nitrerias, o salitre era preparado em um amontoado contendo esterco, cinza de madeira, palha, vegetais e animais em putrefação e urina. A potassa presente nas cinzas convertia o nitro (nitrato) em salitre que, uma vez coletado, passava por uma série de procedimentos técnicos de cristalização e purificação. A massa liquida (água-mãe) que restava ao final desses procedimentos era ainda muito rica em nitro (nitratos de cálcio, magnésio, amônio etc.), de modo que a questão era saber como convertê-lo em salitre.

O desperdício da potassa era causado principalmente pela presença de muriato (cloreto) na água-mãe, que retinha o álcali e formava o muriato de potassa (cloreto de potássio, KCl), o que também comprometia a pureza do produto final. Para evitar essa perda, a solução seria dosar exatamente a quantidade de potassa empregada, pois o sal nitroso precipitava antes que o sal muriato; a potassa tinha maior afinidade com o ácido nitroso (ácido nítrico, $\mathrm{HNO}_{3}$ ) do que com o ácido muriático (ácido clorídrico, $\mathrm{HCl}$ ). Além de propor três métodos de determinação da quantidade de potassa a empregar, Guyton de Morveau aperfeiçoou o modo de determinar o ponto de viragem, utilizando indicadores específicos para cada operação e, sobretudo, construiu um novo instrumento para medir o volume do liquido titulante, a bureta, que em breve tornar-se-ia indispensável em todo laboratório químico (cf. Madsen, 1958).

No início de 1780, ele também recebeu autorização para instalar uma manufatura de vidros em Saint Bérain sur Dheune, próximo a Dijon. O carvão e alguns sais (silicatos) eram obtidos nas proximidades, de modo a formar uma cadeia produtiva a fim de reduzir custos e ganhar escala de produção. Essa vidraria chegou a empregar dezenas de trabalhadores e produzia vidros para vidraças e garrafas de grande qualidade, empregadas no armazenamento dos melhores vinhos da Borgonha (cf. Rorgue, 2006).

$\mathrm{Na}$ manufatura de materiais em vidro era necessário empregar uma substância cuja produção francesa era deficitária. Trata-se da soda (carbonato de sódio, $\mathrm{Na}_{2} \mathrm{CO}_{3}$ ), produto que era obtido de forma artesanal pela queima de plantas marinhas e que era fundamental não apenas nas vidrarias, mas também a uma série de outros procedimentos produtivos (têxteis, sabões, porcelanas, papel etc.). A França dependia largamente da importação de soda produzida na Espanha, o que tornava vulneráveis setores essenciais de sua economia. O estado francês tomou então a decisão de conduzir experiências industriais que pudessem pôr em prática a produção de soda em quantidade economicamente viável. A supervisão ficaria a cargo da Academia de ciências de Paris que, em 1783, também estabeleceu um prêmio a quem conseguisse propor um processo que passasse da produção de laboratório para a de manufatura. 
Por ser membro correspondente da Academia parisiense, Guyton de Morveau não pode participar do concurso. Solicitou, porém, à Câmara de Comércio o direito de construir uma manufatura de soda próxima àquela em que produzia vidros. Os administradores não deram autorização por considerar inviável a produção de soda em uma região com alta gabela, pois isso fazia com que o preço do sal comum ficasse muito elevado. Por exemplo, enquanto um quintal de sal comum (100 kg) custava certa de "1 livres et 10 sous" na Bretanha, em Dijon, o preço seria multiplicado por sete (cf. Déré, 1992, p. 24).

No entanto, o estado dava a autorização, caso a manufatura fosse instalada em uma região livre da gabela e indicava a Bretanha como destino. Foi na região de Le Croisic, próximo de Nantes, cidade que tinha um dos principais portos da França, que o governo central organizou uma "corrida à soda", na qual Guyton de Morveau estava em concorrência com dois outros empreendedores. Em 1783, o químico dijonês instala-se em Nantes para pôr em prática sua nova empreitada, produzir soda a partir do sal comum. Sua estada foi curta, pois outros afazeres da Academia exigiam sua presença em Dijon e seus negócios ficam nas mãos de um administrador.

A primeira tentativa de obter soda artificialmente através do sal marinho (cloreto de sódio, $\mathrm{NaCl}$ ) foi a do químico-agrônomo Duhamel du Monceau, em 1737. Duhamel du Monceau não obteve grande sucesso quanto à quantidade de soda produzida, mas deu duas contribuições importantes: a de diferenciar quimicamente a soda mineral $\left(\mathrm{Na}_{2} \mathrm{CO}_{3}\right)$ da soda vegetal $\left(\mathrm{K}_{2} \mathrm{CO}_{3}\right)$ e a de ter obtido um sal natural $(\mathrm{NaCl})$ através de operações de laboratório, o que tornava indiferente se uma substância era encontrada no ambiente natural ou era produzida artificialmente. $O$ que as identificava era o que elas faziam quimicamente, como se comportavam diante de outras substâncias e em qual região da Tabela de Geoffroy ela se localizavam. Os corpos químicos eram assim o resultado de uma composição material e não portadores de alguma essência constitutiva (cf. Bensaude-Vincent \& Stengers, 1993).

Uma série de dificuldades administrativas e técnicas comprometeram a instalação das manufaturas de soda na Bretanha, frustrando mais essa "aventura industrial" de Guyton de Morveau. Todavia, o mais importante dessa aventura é que ela se insere em uma lógica química de produção que, no caso da soda, será posta em prática logo após a Revolução por Nicolas Leblanc (174:2-1806).

Essa imbricação entre teoria de vanguarda (afinidades químicas ou "o sonho newtoniano"), experimentação (criação de novos métodos e instrumentos) e interesse público (estado, indústria, pesquisa, ensino etc.), que se consolidou no final do século xvıII também faz da química uma ciência paradigmática na análise das origens da noção de "progresso científico". Com Francis Bacon (1561-1626) essa expressão ganhou contornos modernos, mas foi ao longo do século das Luzes que a ideia de pro- 
gresso passou a fazer parte de uma filosofia e de uma prática que tinham por objetivo transformar a sociedade e criar uma nova história.

Dessa maneira, o público que acompanhava os cursos da Academia de Dijon (química, botânica, desenho etc.) almejava participar, seja como ator, seja como observador bem informado, desse movimento progressista. Medir as afinidades químicas, calcular a quantidade exata de uma substância a fim de maximizar o rendimento de uma operação, ou outras inovações teórico-experimentais contribuíam tanto ao progresso humano quanto uma boa qualidade de ensino, a promoção de traduções, de correspondências e de viagens científicas.

Para um público mais amplo, o sonho e a esperança no progresso eram alimentados pelo "espetáculo da ciência”. Não me refiro aqui àqueles espetáculos experimentais cujo objetivo era validar uma determinada teoria, como foi o caso da decomposição da água por Lavoisier, mas a uma relação entre ciência, técnica e indústria visível aos olhos do grande público.

Nos anos 1780, a ciência permitiu ao homem realizar um sonho antigo. O balonismo inaugurado pelos irmãos Montgolfier (1783) vencia a gravidade graças à inteligência e à engenhosidade, mas, sobretudo, à química. No caso dos Montgolfier, que utilizaram o ar atmosférico aquecido, o químico devia selecionar não só o melhor combustível, mas fornecer todos os materiais necessários para construir e proteger o envelope. O desafio técnico, contudo, era produzir e utilizar um ar (gás) mais leve que o ar aquecido, e o principal candidato era o ar inflamável (gás hidrogênio).

Depois de Henry Cavendish e Richard Kirwan, o ar inflamável era considerado como o flogístico em seu maior grau de pureza. Um modo convencional de produzi-lo era mergulhando um metal (zinco, ferro) em ácido vitriólico. Assim, se do ponto de vista técnico a questão era o custo de produção de uma grande quantidade de ar inflamável, essa operação também dizia respeito à outra teoria de vanguarda, a natureza material do flogístico. É bem conhecida a experiência de Lavoisier sobre a decomposi-

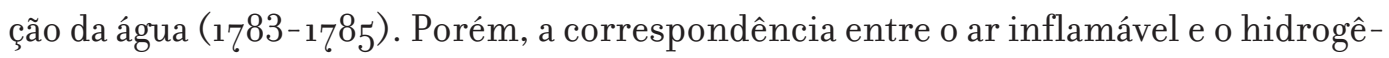
nio (literalmente "formador de água") só será assimilada mais tarde (e com outra explicação que aquela de Lavoisier quanto a sua origem). O estudo de amostras de ar inflamável provenientes de diferentes origens (metais, matéria orgânica, matéria gordurosa etc.) contribuía na caracterização físico-química dessa substância e também no aperfeiçoamento técnico que permitiu ao homem a conquista dos céus.

Após o primeiro voo dos Montgolfier em Annonay e de Pilâtre de Rozier em Paris, iniciou-se uma verdadeira competição entre as cidades e academias científicas francesas no desenvolvimento da aeroestação (aérostation). Essa corrida não mobilizava apenas acadêmicos e inventores, mas a maiorias das corporações de oficio das cidades envolvidas (apoticários, metalúrgicos, cordoeiros, tecelões, envernizadores, papeleiros 
etc.). Fazer um balão voar era o símbolo de um savoir-faire que creditava aos envolvidos publicidade para seus produtos e expectativa de novos negócios. Se a fábrica de papel dos Montgolfier garantia o aporte financeiro necessário à construção de suas máquinas de voar, no caso das academias provinciais somente a subvenção do estado, a cotização entre a população e a contribuição material dos manufatureiros permitia cobrir a considerável soma requerida.

Em Dijon, o professor Guyton de Morveau liderou a empresa baloeira e a pesquisa sobre uma fonte barata de ar inflamável enquadrava-se em suas investigações sobre as propriedades físico-químicas de diferentes tipos de gases (Guyton deixa de utilizar o termo "ar"). Em seu Description de l'aérostate de l'Académie de Dijon, ele descreve as diferentes fontes de gás inflamável, analisa suas propriedades particulares, seu modo de produção e suas densidades relativas. Também propunha uma técnica de navegação que, embora usasse como referência a navegação marítima, lançava as bases da aeronáutica (cf. Guyton de Morveau, 1784b).

A construção do balão da Academia de Dijon mobilizou tanto os manufatureiros quanto a opinião pública da cidade. Solicitou-se uma grande quantidade de peças de tafetá, vernizes que, além de vedar, suportassem a elasticidade da seda, composições metálicas finas e leves para construir os canos e vedações etc. Guyton de Morveau destacava três fontes principais de gás inflamável: a destilação de batatas em decomposição, o ferro com ácido vitriólico e o zinco com esse mesmo ácido. Ele sabia que o gás obtido a partir das batatas não era o mesmo que aquele obtido pela dissolução dos metais, porém era uma forma barata de produzir um gás mais leve que o ar atmosférico (tratava-se do metano). O melhor, ou seja, o mais leve, era o obtido a partir do zinco, porém, era também o mais caro de produzir (devido ao alto preço do metal).

No balão da academia $\left( \pm 350 \mathrm{~m}^{3}\right)$, usou-se uma mistura de $3 / 4$ de gás proveniente da destilação de batatas e 1/4 de gás obtido da dissolução do zinco. Foram realizados dois voos: um em abril de 1784 ( 1 hora $3 \circ$ minutos de duração e $3 \circ$ km percorridos) e o segundo em julho (2 horas 30 minutos e $20 \mathrm{~km}$ percorridos). No caminho de volta, Guyton de Morveau era saudado como herói nos vilarejos em que passava e foi recebido por uma multidão na praça principal de Dijon (cf. Rorgue, 2006).

O balão era uma equação em ato, necessitando do peso exato de todos os elementos que o compõe, além de exigir uma química sofisticada. Sua construção demandava um conhecimento preciso em diversos domínios e requeria a produção em grande quantidade de um gás que passava a ocupar um lugar fundamental no debate sobre a natureza química do flogístico e na nova teoria da composição de Lavoisier. Além de representar uma proeza técnica, a aventura baloeira marcará o espírito público, não só pelo sucesso científico, mas pela dimensão social do espetáculo. O problema, no caso de Dijon, foi o custo altíssimo (4,0 00 libras) desse espetáculo do progresso cien- 
tífico, o que traria sérios incômodos a Guyton de Morveau no seio da academia (cf. Thébaud-Sorger, 2009, p. 297).

Esses exemplos certamente não esgotam os tipos de artefatos e de serviços oferecidos pelo laboratório da Academia de Dijon. Da mesma forma, não limitam os interesses de seus frequentadores à aplicação prática do conhecimento químico. Convém não esquecer, por exemplo, que em torno desse laboratório articulava-se também um importante grupo de tradutores coordenados por Claudine Picardet que vertiam para o francês os textos dos principais químicos alemães, ingleses, suecos e italianos (cf. Bret, 2008). Contudo, espero que esses exemplos sirvam para esboçar o que chamo de "capilaridade técnico-cultural" dos artefatos técnicos, no caso, produzidos pela química, em níveis diversos da sociedade francesa das Luzes.

\section{Conclusão}

Considero que o conceito de "estilo químico" de raciocinar sugerido por BensaudeVincent constitui de fato uma ferramenta analítica de grande interesse, porque nos permite investigar a criação e o desenvolvimento de uma forma química de pensar a materialidade, de projetar sua manipulação bem como sua utilização social. Sugeri, então, chamar de "capilaridade" a disseminação das ideias e dos produtos derivados desses estilos químicos. Aqui, tentei exemplificar tanto o caráter histórico quanto a existência de uma forma de conhecer construída a partir dos laboratórios dos químicos do século das Luzes. Porém, essa contingência histórica não inviabiliza uma abordagem filosófica mais geral, pois não se busca uma definição atemporal do que seria um estilo químico de raciocinar.

Talvez uma vantagem imediata na admissão da existência de um estilo próprio à química consista em não mais restringi-la a uma noção disciplinar. Como a organização disciplinar é relativamente recente, seria interessante considerar o conhecimento químico não apenas como uma disciplina científica, mas como uma maneira de operar sobre a matéria através de conceitos empíricos e teóricos. Ou seja, de um ponto de vista filosófico poderíamos considerar que um estilo químico possibilita uma filosofia da química não apenas preocupada em reafirmar sua identidade ou sua não redutibilidade cognitiva, mas, sobretudo, interessada com as questões filosóficas engendradas pelo conhecimento químico. Outro ganho, penso, é não limitar o interesse filosófico pela química a seus aspectos teóricos, nem o seu desenvolvimento a uma sucessão de revoluções paradigmáticas. É bom lembrar que os “estilos de raciocínio" científico descritos por Hacking não são incomensuráveis entre si, nem se restringem a um conjunto homogêneo de teorias e práticas. 
Enfim, é uma constatação do cotidiano contemporâneo a de que os artefatos químicos estão em toda parte e em parte alguma. Estão distribuídos e organizados em uma rede complexa de relações, que começa com a construção de práticas operacionais e de teorias no laboratório dos químicos, mas se ramificam em múltiplos outros domínios sociais. Da possibilidade técnica de produzi-los a sua disseminação em grande escala, os produtos da química possuem capilaridade não apenas no ambiente natural e nas atividades industriais e agrícolas, mas também na cultura das sociedades em que são produzidos. É importante ressaltar que o empreendimento técnico-científico da química não é algo recente, mas faz parte essencial de sua longa história.

Essa onipresença e desaparecimento não são certamente exclusividade dos artefatos químicos, mas, como apontou Gilbert Simondon, são características marcantes dos artefatos técnicos em geral, bem como um dos indícios de um tipo particular de alienação, aquela engendra pela própria técnica (cf. Simondon, 2012). É nessa direção simondoniana que pretendo orientar investigações ulteriores acerca do conceito de "capilaridade" que aqui apenas esbocei.

Ronei Clécio Mogellin
Departamento de Filosofia

Universidade Federal do Paraná, Brasil.

r.cleciomocellin@gmail.com

\title{
Style of reasoning and technical-cultural capillary action in the Chemistry of 18 th century
}

\begin{abstract}
In this paper I will identify a "style of reasoning" that is proper to to Chemistry and to point to the dissemination of its products and concepts. My aim is to explain some elements that characterize the style of thinking and engaging in Chemistry in the second half of the $18^{\text {th }}$ century, its techno-cultural capillary action. The shaping of a chemical style of reasoning originated from the constancy of the techno-epistemic sites in which chemical knowledge is formed. Chemistry is a laboratory science, eminently technical and operative, i.e., it deals with a techno-scientific knowledge stricto sensu. A producer of artifacts, chemical science is inseparable from technique, technology and industry, in such a way that its epistemic identity is inseparable from its history. Its style marks a profound value in the technical culture of the homo faber, the power of acting upon nature and transforming it through manipulations and rearrangements.
\end{abstract}

KEYwords $\bullet$ Style of chemical reasoning. Laboratory. Technical-cultural capillary action. 18th century. Academy of Dijon. Technoscience. 
EsTiLO DE RAGIOCÍNIO E GAPILARIDADE TÉGNIGO-GULTURAL NA QUÍMIGA NO SÉGULO XVIII

\section{REFERÊNGIAS BIBLIOGRÁFIGAS}

Affiches, annonces et avis divers, ou Journal de la Bourgogne, Dijon, 2 Avril 1776. Bibliothèque Municipale de Dijon, Fonds anciens.

Applebaum, W. (Ed.). Encyclopedia of the scientific revolution. From Copernicus to Newton. New York/London: Garland, 2000.

Baird, D. et al. (Ed.). Philosophy of chemistry. Dordrecht: Springer, 2006.

Bensaude-Vigente, B. Chemistry: the impure science. Singapore: Imperial College Press, 2008a. Matière à penser. Essais d'histoire et de philosophie de la chimie. Paris: Presses Universitaires de Paris Ouest, 2008b.

The chemist's style of thinking. Berichte zur Wissenschaftsgeschichte, 32, p. 365-78, 2009.

Bensaude-Vigente, B. \& Stengers, I. Histoire de la chimie. Paris: La Decouverte, 1993.

Beretta, M. Big chemistry: Lavoisier's design and organization of his laboratories. In: Lourenço, M. C. \& Carneiro, A. (Ed.). Spaces and collections in the history of science: the Laboratorio Chimico Overture. Lisboa: Museum of Science of the University of Lisbon, 2009. p. 65-80.

Bergman, T. Opuscules chymiques et physiques. Dijon: Frantin, 1780.

BRET, P. Lavoisier à la régie des poudres: le savant, le financier, l'administrateur et le pédagogue. La Vie des Sciences. Comptes rendus de l'Académie des Sciences, 11, 4, p. 297-317, 1994.

Les promenades littéraires de madame Picardet. La traduction como pratique sociale de la science au xviıre siècle. In: Duris, P. (Org.). Traduire la science, hier et aujourd'hui. Pessac: Maison des Sciences de l'Homme d'Aquitaine, 2008. p. 125-52.

Свомвіе, A. Styles of scientific thinking in the european tradition. The history of argument and explanation. Especially in the mathematical and biomedical science and arts. London: Duckworth, 1994. $3 \mathrm{v}$.

Dagognet, F. Tableaux et langages de la chimie. Paris: Champ Vallon, 2002.

Demeulenaere-Douyère, C. \& Brian, E. (Org.). Règlement, usages et science dans la France de l'absolutisme. Paris: Tec\&Doc, 1999.

Déré, A-C. Economie portuaire, innovation technique et diffusion restreinte: les fabriques de soude dans la région nantaise (1777-1815). Sciences et Techniques en Perspective, 22, p. 1-176, 1992.

Duhamel du Monceau, H. D. Sur la base du sel marin. Mémoires de l'Académie Royale des Sciences - Année 1736. Paris: Imprimerie Royale, p. 215-32, 1739.

Duris, P. (Org.). Traduire la science, hier et aujourd'hui. Pessac: Maison des Sciences de l'Homme d'Aquitaine, 2008.

EKLund, J. The incompleat chymist. Washington: Smithsonian Institution Press, 1975.

FLECK, L. Gênese e desenvolvimento de um fato científico. Belo Horizonte: Fabrefactum, 2010.

Goodman, N. Modos de fazer mundo. Porto: ASA, 1995.

GuYton de Morveau, L. B. Expériences sur l'attraction ou la répulsion de l'eau \& des corps huileux, pour vérifier l'exactitude de la méthode par laquelle le Docteur Taylor estime la force d'adhésion des surfaces, \& détermine l'action du verre sur le mercure des baromêtres. Observations sur la physique, sur l'histoire naturelle et le arts. Paris: Rozier, 1773. t. 1, p. 168-73.

Mémoire sur l'utilité d'un cours public de chimie dans la ville de Dijon: les avantages qui en résulteroient pour la Province entiere, \& les moyens de procurer à peu de frais cet Etablissement. Dijon: Frontin, 1774 .

Élémens de chymie, théorique et pratique. Dijon: Frontin, 1777-1778. 3 t.

Sur les moyens de saturer les eaux-meres du nitre, sans perte de l'alkali \& pour éviter le mélange du muriate de potasse ou sel de sylvius avec le salpêtre. Nouveaux Mémoires de l'Académie de Dijon, p. 126,1782 .

. Méthode facile pour mesurer la quantité de gas acide méphitique contenu dans les eaux. Nouveaux Mémoires de l'Académie de Dijon, p. 85-9, 1784a. 
Guyton de Morveau, L. B. Description de l'aérostate de l'Académie de Dijon. Dijon: Causse Imprimeur du Parlement, 1784 b.

Hacking, I. Ontologia histórica. São Leopoldo: Unisinos, 2002.

. Linguagem, verdade e razão. In . Ontologia histórica. São Leopoldo: Unisinos, 2002a. p. 17998.

Estilo para historiadores e filósofos. In: . Ontologia histórica. São Leopoldo: Unisinos, 2002b. p. 199-220.

."Language, truth and reason": 3o years later. Studies in History and Philosophy of Science, 43, p. 599$609,2012$.

Holmes, F. L. Eighteenth-century chemistry as on investigative enterprise. Berkeley: University of California Press, 1989.

Kıм, M. G. Affinity, that elusive dream: a genealogy of the chemical revolution. Cambridge: The MIT Press, 2003.

KLein, U. \& Lefèvre, W. Materials in eighteenth-century science-a historical ontology. Massachusetts: The MIT Press, 2007.

Kwa, C. An "ecological" view of styles of science and of art: Alois Riegl's explorations of the style concept. Studies in History and Philosophy of Science, 4,3, p. 610-8, 2012.

Lamarre, C. L'organisation de la discussion scientifique autour de Guyton de Morveau et de Maret: l'Académie de Dijon entre 1780 et 1788. In: Demeulenaere-Douyère, C. \& Brian, E. (Org.). Règlement, usages et science dans la France de l'absolutisme. Paris: Tec\&Doc, 1999. p. 193-3०5.

. François Devosge, Louis-Bernard Guyton de Morveau, Hugues Maret et les couleurs à l'Academie de Dijon au xvıı siècle. Bulletin des Musées de Dijon, 6, p. 49-53, 2000.

Lavoisier, A. Traité élémentaire de chimie. Paris: Cuchet, 1789.

LeFÈvre, W. Science as labor. Perspectives on Science, 13, 2, p. 194-225, 2005.

Lehman, C. Les deux faces de la chimie de Venel: côté cours, côté Encyclopédie. Corpus Revue de Philosophie, 56, p. $87^{-116,2009 .}$

Lourenço, M. C. \& CARneiro, A. (Ed.). Spaces and collections in the history of science: the Laboratorio Chimico Overture. Lisboa: Museum of Science of the University of Lisbon, 2009.

Macquer, P. J. Dictionnaire de chymie. Paris: Lacombe, 1766. 2v.

Lettres de Guyton de Morveau à Macquer, Bibliothèque National de France Ms.123o6, fo 175-206, $1769-1784$.

Madsen, R. The development of titrimetric analysis til 1806. Copenhaguen: G.E.G. Gad Publisher, $195^{8}$.

Mocellin, R. G. Louis-Bernard Guyton de Morveau: chimiste et professeur au siècle des lumières. Saarbrücken: Éditions Universitaires Européennes, 2010.

Perkins, J. (Ed.). Sites of chemistry in the eighteenth century. Ambix, 6o, 2, p. 95-8, 2013.

Rorgue, F. Guyton de Morveau en Bourgogne: itinéraire d'un dijonnais au xviıe siècle et sous la révolution (1737-1791). 2006. Mémoire de master II. Université de Bourgogne, 2006.

Schummer, J. The notion of nature in chemistry. Studies in History and Philosophy of Science, 34, p. 70536, 2003.

Simondon, G. Du mode d'existence des objets techniques. Paris: Aubier, 2012.

Sмith, P. Laboratories. In: Applebaum, W. (Ed.). Encyclopedia of the scientific revolution. From Copernicus to Newton. New York/London: Garland, 2000. p. 547-50.

Thébaud-Songer, M. L'aérostation au temps des lumières. Paris: Presses Universitaires de Rennes, 2009.

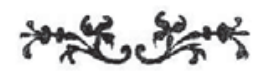

